\title{
PODER JUDICIÁRIO E MEIOS DE COMUNICAÇÃO: DO DEVER DE TRANSPARÊNCIA AOS RISCOS DE EXPOSIÇÃO MIDIÁTICA
}

\author{
THE JUDICIAL SYSTEM AND MASS MEDIA: FROM THE \\ DUTY OF TRANSPARENCY TO THE RISKS OF MEDIA \\ EXPOSURE
}

ROSIMEIRE VENTURA LEITE

Pós-Doutora em direito pela Universidade de Bologna - Unibo. Doutora em processo penal pela USP. Professora de direito processual penal da UEPB. Juíza de direito do TJPB. Professora do PPGPD/Enfam. https://orcid.org/0000-0002-4546-5616

\section{RESUMO}

O artigo tem como objetivo analisar os desafios da comunicação do Poder Judiciário na sociedade contemporânea, especificamente quanto à relação com os meios de comunicação, incluídas as mídias digitais. Pontua-se que o Poder Judiciário é chamado a estabelecer novo paradigma de interação com a sociedade, diante da consolidação do dever de transparência das instituições públicas, bem como do acelerado fluxo de informações promovido pelos avanços tecnológicos. Tem-se como arcabouço teórico as transformações ocorridas com o advento da globalização e da pós-modernidade, as quais repercutem nas instituições, exigindo adaptação constante. Aborda-se, por fim, a midiatização da Justiça e seus impactos, enfatizando-se a necessidade de aprimorar o planejamento da comunicação institucional e da gestão dos riscos decorrentes da exposição midiática.

Palavras-chave: Poder Judiciário; comunicação; mídia; transparência; midiatização da justiça.

\section{ABSTRACT}

This article aims to analyze the challenges of communication the Judicial System has in current society, specifically regarding the mass media which include social medias. The Judicial System has been drawn to establish a 
new paradigm of interaction with society, considering the consolidation of the duty of transparency for public institutions, as well as the fast flux of information caused by technological advances. Our theoretical framework considers the changes occurred with the advent of globalization and postmodernity, which affect institutions and demand their constant adaptation. Finally, the mediatization of the Judicial System and the consequent impacts are approached, with emphasis on the need to prime the planning of institutional communication and management of consequent risks of media exposure.

Keywords: judicial system; communication; media; transparency; mediatization of the judicial system.

Recebido: 20-6-2021

Aprovado: 28-6-2021

\section{SUMÁRIO}

1 Introdução. 2 Breves notas sobre a comunicação na era digital. 3 Comunicação do Poder Judiciário na sociedade global e pós-moderna. 4 Dever de transparência como valor democrático. 5 Comunicação pública e comunicação institucional do Poder Judiciário. 6 Impactos da midiatização da Justiça. 7 Comunicação do Poder Judiciário e gestão de riscos no planejamento estratégico. 8 Conclusão. Referências.

\section{INTRODUÇÃO}

A relação entre o Poder Judiciário e a mídia é comumente retratada como conflituosa, sobretudo pelos diferentes modos de atuação. Enquanto o primeiro caracteriza-se pela reserva, pela observância de rituais e procedimentos, bem como por certo distanciamento, os meios de comunicação, ao contrário, perseguem a notícia mais atrativa e são movidos por interesses e dinâmicas que Ihe são peculiares. Tais divergências ficam bem evidentes quando se trata da narrativa midiática sobre processos judiciais. Contudo, para além da curiosidade que o desfecho de determinados casos levados ao crivo da Justiça gera para a coletividade, o próprio Poder Judiciário e a conduta de seus membros passaram a ser alvo de atenção. De fato, a exigência de transparência e abertura democrática das instituições públicas possibilitou maior disponibilidade de informações sobre o funcionamento delas, tendo como consequência repercussões positivas ou negativas junto à opinião 
pública. Por outro lado, comportamentos individuais de magistrados, seja na condução de processos, seja na vida privada, tornaram-se igualmente matéria-prima para notícias.

A forma de se comunicar da sociedade contemporânea também passou por profundas modificações. Desde a popularização da televisão e do rádio, a ideia de massificação reinventou-se, notadamente com a comunicação digital e seus diversos instrumentos de interação, que transformam qualquer indivíduo em potencial formador de opinião pública. Sendo assim, em uma sociedade em que a informação tem papel central, cabe indagar como o Poder Judiciário pode aprimorar a capacidade de comunicação, cumprindo com o dever de transparência e, ao mesmo tempo, preservando sua imagem e credibilidade, por vezes postas em risco por exposições midiáticas. Trata-se de temática bastante atual, pois diz respeito diretamente à necessidade de adaptação do Poder Judiciário e de fortalecimento institucional em cenários sociais cada vez mais complexos.

Desse modo, o artigo tem como objetivo analisar os novos desafios da comunicação do Poder Judiciário no contexto social contemporâneo, contribuindo para o debate sobre como a relação entre Poder Judiciário e mídia pode ser reestruturada para o fortalecimento do sistema de justiça.

\section{BREVES NOTAS SOBRE A COMUNICAÇÃO NA ERA DIGITAL}

Os avanços da tecnologia da informação representam um dos fenômenos mais notáveis da sociedade contemporânea, possibilitando formas de interação cada vez mais velozes e desconectadas de limites territoriais. Seguindo o panorama traçado por Bentivegna e Artieri, vê-se que o marco inicial para compreensão desse contexto remete à própria construção da ideia de sociedade de massa e, posteriormente, de comunicação de massa, conceitos que começaram a se delinear a partir do processo de industrialização e urbanização ocorrido no final do século XIX. Nesse sentido, a massa, na sua origem, identificava-se, nos estudos políticos e sociológicos, como um conjunto indiferenciado de indivíduos, caracterizado pela desorganização, irracionalidade e facilidade de manipulação. No seio dessa nova estrutura social, os meios de comunicação ganharam particular atenção, devido à capacidade de transmitir mensagens a uma grande quantidade de pessoas, surgindo 
a preocupação sobre quais tipos de influências poderiam ser exercidas. Desse modo, as indagações iniciais sobre os meios de comunicação de massa se concentravam no poder de manipulação da imprensa e do rádio, notadamente no período das Grandes Guerras. (BENTIVEGNA; ARTIERI, 2019, p. 5-15)

ponto de partida para esses estudos foi a denominada Teoria Hipodérmica, pela qual os meios de comunicação exerceriam uma influência direta sobre o público, em uma relação de estímulo e resposta que não considerava outros elementos (BENTIVEGNA; ARTIERI, 2019, p. 12). Essas teorias, contudo, sofisticaram-se e se multiplicaram ao longo do tempo, impulsionadas por pesquisas empíricas. Dentre elas, pode-se destacar a Teoria do Agendamento, ou agenda-setting, segundo a qual, em síntese apertada, os meios de comunicação de massa fazem uma seleção de temas que merecem ser noticiados e transferem a relevância desses temas para a agenda do público. Seria, então, uma forma de influenciar os individuos sobre quais matérias devem ser objeto de atenção, como devem ser interpretadas e até mesmo a correlação entre os temas. (BENTIVEGNA; ARTIERI, 2019, p. 168-185)

O surgimento da televisão e sua expansão após a Segunda Guerra Mundial acrescentou nova etapa no fenômeno dos mass media, intensificando a exposição do público ao conteúdo veiculado por esses meios. Contudo, foi com o advento da internet que se firmaram as possibilidades de interação em rede, o que decorreu de um conjunto de avanços na tecnologia da informação e da comunicação, verificados ao longo das últimas décadas do século passado. Esses progressos são qualificados por Castells como verdadeira revolução, considerando o amplo impacto que promoveram "em todas as esferas da atividade humana” (CASTELLS, 2020, p. 64). A comunicação, portanto, entrou na fase da virtualidade, da instantaneidade, da ampla segmentação de públicos e da intensidade sem precedentes de circulação das informações. Aos meios de comunicação tradicionais, representados principalmente pela imprensa escrita, o rádio e a televisão, somaram-se as mídias digitais, com seus múltiplos canais de produção e difusão de conteúdo.

Por conseguinte, com o ingresso na era da comunicação digital, a própria concepção de massa e de comunicação de massa passou por modificações, como observam Bentivegna e Artieri. Se durante várias décadas a comunicação tradicional esteve fundada na homogeneidade, paulatinamente esse padrão foi sendo alterado, para atender aos 
anseios e às características de um público cada vez mais segmentado. Essa trajetória, então, intensificou-se com a conexão possibilitada pelas redes sociais e as plataformas, conduzindo à percepção de que os indivíduos não eram apenas receptores de mensagens, mas também sujeitos ativos no processo de comunicação. (BENTIVEGNA; ARTIERI, 2019, p. 23-39)

O que se tem, na atualidade, não é mais, exclusivamente, uma mensagem difundida para um público indiferenciado e com baixa ou nenhuma oportunidade de interação, mas sim um contexto no qual cada indivíduo é receptor e produtor da mensagem. Esse é um sistema que Castells caracteriza como sendo de "autocomunicação de massa", ou seja, uma comunicação autogerada e que atinge potencialmente grande número de pessoas, até mesmo em esfera global (CASTELLS, 2017, p. 102). É nessa perspectiva também que o filósofo Han traz a ideia de que as mídias digitais, na realidade, promovem a "desmediatização", pois cada vez mais a comunicação ocorre sem intermediários, diferentemente da dinâmica característica das mídias tradicionais, como rádio e televisão, que atuam efetivamente como meios de produção e transmissão da mensagem. (HAN, 2019, p. 35-42)

São profundos, pois, os impactos dessas transformações, redimensionando hábitos, estilos de vida, expectativas, relações interpessoais, formas de mobilização social, dentre outros aspectos. Os meios de comunicação, incluindo as mídias digitais, estão mais presentes do que nunca nas mais diferentes esferas da existência humana. Tanto indivíduos quanto instituições experimentam o desafio de compreender e de se adaptar a essa realidade, na qual informação, conexão, imagem e espetáculo fazem parte do cotidiano.

\section{COMUNICAÇÃO DO PODER JUDICIÁRIONA SOCIEDADE GLOBAL E PÓS-MODERNA}

O progresso tecnológico que viabilizou a mudança de paradigma comunicacional é uma das facetas de um contexto social mais amplo, que abrange as transformações promovidas pela globalização e pela pós-modernidade. A globalização, consolidada a partir da segunda metade do século XX, representou um conjunto de profundas mudanças políticas, econômicas e culturais, com impactos sobre distribuição do poder, mercados, relações de trabalho e estilos de vida. Conforme destaca lanni (2004, p. 13), mais do que um momento de "universalização 
do capitalismo", a globalização trouxe consigo um verdadeiro "processo civilizatório". Trata-se, pois, de um fenômeno que "abrange todos os campos das atividades humanas", conduzindo a uma "sociedade planetária e aberta". (ARNAUD, 2004, p. 39)

Com a globalização teve-se também significativo redimensionamento da relação tempo-espaço. O presente e o efêmero erigiram-se a lugar privilegiado e as barreiras territoriais foram continuamente superadas, tudo na mesma lógica da aceleração da produção e dos fluxos de mercadorias (HARVEY, 2006, p. 257-276). A isso agregou-se, como fator de interpretação da realidade social, o desgaste de diversos paradigmas criados na modernidade, relacionados a valores, princípios e modos de atuação. Esse período de rupturas, adaptações e incertezas é comumente denominado pós-modernidade, hipermodernidade ou modernidade líquida, dentre outras terminologias utilizadas (BITTAR, 2005, p. 123-137). Fluidez das relações, consumismo, fragilização do Estado e de suas instituições, confronto de ideologias e dificuldades de obter consensos são algumas das manifestações associadas às crises instaladas nessa fase.

As instituições tradicionais, fruto da construção do Estado moderno, têm sido diretamente atingidas por esse cenário sociocultural, político e econômico cada vez mais exigente e multifacetado trazido pela globalização e pelo pós-modernismo. Práticas, procedimentos e valores antes tidos como adequados já não oferecem respostas satisfatórias, gerando riscos de perda de legitimidade. Em vários sentidos, evidenciase a necessidade de adaptação dessas instituições, a exemplo da forma pela qual se comunicam e realizam seus processos decisórios.

Nessa esfera, destaca Ferrarese (2002, p. 63) que o "senso hipertrófico do presente", advindo da globalização e dos avanços tecnológicos, impõe nova dinâmica, em que "os tempos mais lentos das instituições tradicionais" são "continuamente desafiados pelos tempos sempre mais breves da comunicação social”. De igual modo, a velocidade de reação não pode ser a mesma de épocas anteriores, pois o ritmo de transmissão das informações, inaugurado com a internet, "supera os tempos de decisão humana no interior das estruturas rígidas de uma organização tradicional". (AUBERT, 2003, p. 216-217)

Nessa conjuntura, as repercussões também se fazem sentir no Poder Judiciário, que é chamado a lidar com fenômenos sociais diversos, como o reconhecimento de novos direitos, as transformações tecnológicas, o aumento da litigiosidade, o surgimento de demandas complexas pela 
extensão dos direitos violados ou pela transnacionalização das práticas delitivas, dentre outros. A forma como o Poder Judiciário interage com essa sociedade em constante mutação - sociedade líquida, na expressão de Bauman (2001) - é ponto crucial no processo de reinvenção institucional que ora se enfrenta, o que passa por sua capacidade de desenvolver uma comunicação mais eficiente e ajustada às exigências contemporâneas.

Esse arcabouço, portanto, é necessário para compreender os desafios do Poder Judiciário na denominada sociedade da informação, globalizada e pós-moderna, partindo-se do pressuposto de que as reflexões sobre o atuar desse Poder vão muito além do universo jurídico, exigindo a contextualização na pluralidade e na complexidade dos dilemas atuais.

\section{DEVER DE TRANSPARÊNCIA COMO VALOR DEMOCRÁTICO}

Um dos aspectos fundamentais do processo de adaptação das instituições públicas às novas exigências sociais refere-se à necessidade de assegurar mais transparência em suas práticas. Posturas de distanciamento do cidadão comum e baixa acessibilidade tornaramse insustentáveis, diante da expectativa de maior participação e conhecimento sobre o modo pelo qual o poder é exercido. A busca pelo fortalecimento da democracia requer o conhecimento acerca de como funcionam as instituições públicas, possibilitando controle sobre a efetiva adesão aos interesses da coletividade. O instrumento para tanto é o acesso à informação. Tal contexto, fundado no anseio por transparência, conduz à reflexão sobre que ações o Poder Judiciário tem adotado para gerar proximidade e difundir informações sobre o desenvolvimento de suas atividades.

A transparência, termo que surgiu em meados da década de 1970 (CHEVALLIER, 1988, p. 239), e cujo conceito relaciona-se com aquilo que se deixa revelar, ao contrário do que é opaco, erigiu-se como valor de particular relevância a partir das rupturas paradigmáticas que emergiram na sociedade contemporânea. Sobre a matéria, Han destaca que a transparência tornou-se um "tema totalizante", que "abarca todos os processos sociais, submetendo-os a uma modificação profunda". Por consequência, o anseio por transparência não se refere apenas à seara pública, às questões políticas, mas também à esfera individual, de 
maneira que, nos mais diversos segmentos da vida, passa a vigorar uma verdadeira expectativa de exposição (HAN, 2017, p. 9-10). Trazendo a discussão para o âmbito das questões públicas, observa-se que a abertura das instituições, atendendo aos ditames da transparência, não se deu por um processo espontâneo, mas sim como movimento imperativo propulsionado por múltiplos fatores socioculturais, econômicos e políticos da pós-modernidade e da globalização, dentre eles a própria crise de legitimidade do Estado, enquanto construção moderna.

- modelo clássico de relação da administração pública com o cidadão comum, esclarece Chevallier, era fundado no segredo, como forma de proteção e reserva, bem como no distanciamento, com exercício unilateral da autoridade. No entanto, a partir de dado momento socio-histórico, o segredo, como instrumento de preservação do atuar administrativo, adquiriu conotação negativa, gerando desconfianças por parte dos administrados. Isso ocorreu na medida em que foram aumentando as aspirações por participação cidadã, associado ao fortalecimento do direito à informação e à consolidação dos valores democráticos. Nessa perspectiva, o segredo foi vinculado a posturas autoritárias, e a transparência a um novo paradigma de relacionamento com o cidadão, apta, sobretudo, a garantir mais legitimidade à administração da coisa pública (CHEVALLIER, 1988, p. 244-245). Na mesma linha, Ferrarese pontua que as instituições da "primeira modernidade", direcionadas ao controle do indivíduo, usavam sua capacidade comunicativa "mais em favor do poder do que da sociedade". Posteriormente, a comunicação institucional passou a considerar também as influências provenientes da sociedade, tornandose bidirecional. (FERRARESE, 2002, p. 60) ${ }^{1}$

No Brasil, assim como em outros países da América Latina, a tendência global de maior controle das instituições públicas através do acesso à informação só tornou-se possível com a superação dos regimes autoritários. A definição de um marco legal para tanto foi imprescindível, com destaque para a Constituição Federal de 1988 e para a Lei de Acesso à Informação de 2011 (Lei n. 12.527), o que demonstra que, historicamente, é um movimento ainda bem recente. No âmbito do Poder Judiciário, por sua vez, a referência é a Resolução n. 215/2015, editada pelo Conselho Nacional de Justiça.

Observe-se que a autora utiliza o termo "primeira modernidade" como o período que antecede o fenômeno da globalização, que seria a "segunda modernidade". 
A disponibilidade de dados sobre o funcionamento das instituições e a redução dos espaços nos quais se recorre ao segredo configuram-se como elementos fundamentais do controle do exercício do poder, medida imprescindivel para a consolidação de uma sociedade democrática, em que a participação e a cidadania sejam valorizadas, em detrimento de interesses individuais de grupos e governantes. Por outro lado, para que essas iniciativas atendam à sua finalidade de inclusão e de respeito à res publica, devem assegurar informações de qualidade ao cidadão, pois, conforme adverte Han, mais informação não garante necessariamente mais verdade. (HAN, 2017, p. 96)

Ao incorporar esses valores de transparência, acessibilidade e proximidade, o Poder Judiciário adapta-se às novas exigências e constrói uma relação com a sociedade passível de reforçar positivamente sua imagem como um dos pilares da democracia. Diversas informações, então, tornaram-se disponíveis, a exemplo de orçamento, licitações, produtividade, remuneração, possibilitando o amplo conhecimento por parte dos atores sociais interessados. Do mesmo modo, os canais de interação com o público se diversificaram com os progressos tecnológicos, expandindo os meios de acesso à justiça.

A comunicação com o público configura-se, portanto, como questão altamente estratégica, pois é instrumento essencial para concretizar a própria noção de transparência e de acessibilidade. Nessa perspectiva, os meios de comunicação, sejam os tradicionais ou as novas mídias, exercem papel relevante. Para Binder (2004, p. 257-260), o trabalho realizado por esses meios se destaca, dentre outros aspectos, por permitir "a crítica social acerca da justiça", bem como por ajudar a decodificar "a complicada linguagem judicial", que é um dos fatores de distanciamento do cidadão comum em relação aos assuntos do Poder Judiciário. Quanto às mídias digitais, possibilitam interação rápida e direta com os jurisdicionados, aumentando a visibilidade sobre ações institucionais e criando engajamento em campanhas.

\section{COMUNICAÇÃO PÚBLICA E COMUNICAÇÃO INSTITUCIONAL DO PODER JUDICIÁRIO}

O cenário acima relatado conduz ao entendimento de que as instituições públicas, e especificamente o Poder Judiciário, mais do que nunca precisam aprimorar sua capacidade de dialogar com a sociedade, o que requer mudança cultural e aperfeiçoamento de gestão. Formas 
de comunicação excessivamente solenes e formais podem não atingir adequadamente o público, além disso, a velocidade com a qual a informação é produzida e propagada atualmente exige sensibilidade e profissionalismo quanto ao melhor momento para resposta. Se a comunicação eficiente é tida, desde longa data, como fator crucial de sucesso na esfera privada, o mesmo não se verifica no setor público, que só mais recentemente tem sido confrontado com essa problemática.

A comunicação no setor público tem a particularidade de ser instrumento de construção da cidadania, promovendo a integração, a conscientização sobre direitos e a correta prestação de contas. $\mathrm{Na}$ definição de Castro (2019, p. 48), é uma comunicação que "atua sob a perspectiva do interesse coletivo, a fim de colaborar para que as instituições se tornem mais democráticas, acessíveis e eficientes para a população". Por conseguinte, não pode ser confundida com "propaganda, controle, manipulação de informação, cerceamento de acesso e proselitismo de interesse de cúpulas" (DUARTE, 2019, p. 58). Pelo contrário, a comunicação pública deve ter como foco a conexão com a coletividade, a fim de compreender suas necessidades e, assim, melhorar a qualidade dos serviços.

Certamente, os recursos tecnológicos disponíveis são indispensáveis para a execução de uma política eficaz de comunicação no setor público, pois permitem levar informações com mais rapidez e abrangência. Possibilitam ainda dialogar com uma sociedade que se caracteriza por ser hiperconectada, muito embora seja forçoso reconhecer que muitos ainda são excluídos digitais. Contudo, para além das vantagens trazidas pela tecnologia, importa destacar que a comunicação pública vai além dessa perspectiva, devendo, na verdade, ser reflexo de uma cultura organizacional que valorize, sobretudo, a proximidade e a transparência. Nesse sentido, a comunicação pública e institucional deve ser realizada com a visão "integrada e sistêmica" de que trata Castro (2019, p. 48-50), de modo que a interação de qualidade seja priorizada desde o atendimento mais básico de balcão até o acompanhamento das mídias digitais.

É de se admitir, portanto, que as instituições públicas precisam se empenhar para ganhar maturidade em termos de comunicação, o que é vital para preservar legitimidade e respeitabilidade nesse cenário social movido pelo consumo de informações. O Poder Judiciário, frequentemente tido como inacessível e distante, seja pelo linguajar utilizado, seja pela reserva que the é própria e até certo ponto exigível, 
tem o desafio de aperfeiçoar seus mecanismos de diálogo com a sociedade. E, dentro dessa temática ampla da comunicação do Poder Judiciário, insere-se também a discussão específica da relação com os meios de comunicação de massa, sejam os tradicionais ou as mídias digitais, considerando que representam uma fonte crucial de produção e difusão de informações sobre os assuntos do sistema de justiça.

De fato, o cidadão comum ainda tem pouca compreensão acerca das atividades desenvolvidas pelo Poder Judiciário. Isso é comprovado por pesquisa nacional indicativa de que "apenas 5\% da sociedade se considera bem informada" sobre o funcionamento da Justiça (AMB; FGV; IPESPE; 2019, p. 30). Esse desconhecimento pode contribuir para que as pessoas tenham baixa capacidade de análise crítica das informações que chegam até elas sobre o Poder Judiciário. Assim, eventos negativos isolados, noticiados pelos meios de comunicação ou postados em redes sociais, têm potencial aumentado de induzir a generalizações que não correspondem à realidade. Não basta que os magistrados sejam produtivos, engajados e independentes, se isso não for percebido pela população, por falhas de comunicação e de iniciativas que reforcem os laços de confiança da sociedade em relação ao Judiciário.

A comunicação institucional, portanto, é imprescindível para que o Poder Judiciário esteja cada vez mais apto a produzir e difundir informações que lhe digam respeito e que contribuam para a construção de bases sólidas na convivência com os diversos atores sociais. Se a própria Justiça não tiver protagonismo na consolidação de sua imagem, certamente outros assumirão esse papel, estabelecendo filtros que nem sempre serão favoráveis. Como destaca Santos (2011, p. 121), "a administração da justiça será tanto mais legitimada pelos cidadãos quanto mais conhecida e reconhecida for por eles".

A expectativa de uma Justiça mais transparente e democrática impulsiona, por sua vez, um relacionamento necessariamente mais próximo entre o Poder Judiciário e os meios de comunicação, considerando que grande parte das informações sobre o funcionamento da Justiça, que chega ao público, advém desses canais. Isso exige o enfrentamento das clássicas resistências entre ambos, em prol de respostas mais satisfatórias às particularidades da sociedade contemporânea, como pondera Santos (2011, p. 121). Assim, importa reconhecer que os meios de comunicação e a rede de interação gerada pelas mídias digitais podem ser aliados importantes na propagação de informações que conectem o cidadão comum ao Judiciário, não obstante as cautelas 
que, igualmente, devem guiar as discussões nessa matéria, tendo em vista as distinções existentes entre os dois universos.

\section{IMPACTOS DA MIDIATIZAÇÃO DA JUSTIÇA}

O interesse da sociedade e dos meios de comunicação pelo ambiente judiciário não é recente, sobretudo no que diz respeito ao acompanhamento de determinados processos judiciais que atraem a curiosidade do público quanto ao seu desfecho, de regra envolvendo apuração de crimes. Contudo, novos fatores acrescentaram pontos de reflexão nessa problemática. $\bigcirc$ primeiro deles refere-se à consolidação do dever de transparência, medida que ampliou a visibilidade das instituições públicas e o acesso a informações antes mais reservadas. Com isso, outros aspectos do funcionamento do Poder Judiciário, para além da resolução de demandas judiciais, passaram a ser alvo de atenção midiática, a exemplo de questões orçamentárias, remuneração, produtividade e casos de desvios de conduta. De fato, com a redução da opacidade, as instituições foram submetidas a maior nível de exposição, ampliando-se as possibilidades de críticas, haja vista que as disfunções internas ficaram mais perceptíveis. Tudo isso, porém, faz parte da sociedade democrática e dos mecanismos de controle e fiscalização necessários ao bom exercício de qualquer poder.

O segundo fator a ser elencado é o protagonismo que o Poder Judiciário tem alcançado nos últimos anos, com a reabertura democrática do Estado brasileiro e a emergência de novos direitos assegurados pela Constituição Federal de 1988, com aumento da quantidade e da complexidade das demandas. Verificou-se ainda o incremento da exigência de intervenção do Poder Judiciário para suprir lacunas ou violações de direitos, por vezes decorrentes de falta de atuação dos demais poderes na concretização de políticas públicas. Dessa forma, o Brasil aliou-se à tendência global de ampliação do papel social e político do Judiciário, fenômeno que, conforme destaca Santos (2011, p. 30), trouxe expectativas, visibilidade e novas fontes de problemas.

O terceiro aspecto é a mudança de paradigma comunicativo da sociedade global, com o intenso processo de interação proporcionado pelos progressos tecnológicos, aliado ao alcance e à velocidade do fluxo de informações. Aos meios de comunicação tradicionais agregaram-se as mídias digitais, abrindo novos canais de diálogo com a sociedade, 
mas também trazendo necessidades específicas de adaptação da comunicação institucional. Em outras palavras, esses meios tanto podem contribuir para aproximar o Poder Judiciário do público, inclusive com o uso de linguagem mais simplificada, como para propagar, de maneira descontrolada, informações negativas da instituição ou de algum de seus membros.

Essas circunstâncias, portanto, concorrem para que o Poder Judiciário seja assunto de interesse para a agenda midiática, transformando-se em "uma fonte quase ilimitada de eventos passíveis de constituir uma informação" (DUFOUR, 2019, p. 11-12). A seletividade dos temas que compõem essa agenda e que devem ser objeto de notícia nos meios de comunicação tradicionais segue uma lógica própria, muitas vezes focada na preferência pela divulgação de eventos negativos com potencial de escândalo, tendo em vista que essas matérias atraem o público e garantem audiência. Por consequência, uma iniciativa inovadora adotada pelo Poder Judiciário em benefício do jurisdicionado pode passar despercebida, enquanto a suspeita de um desvio de conduta, ainda que isolada e sujeita a apurações, pode ter amplo espaço midiático. Já nas mídias sociais, qualquer pessoa pode relatar experiências diretamente vivenciadas com a Justiça, comentar processos ou mesmo a atuação de um magistrado no exercício de suas funções. Nessa perspectiva, vale a observação de Santos (2011, p. 30) ao mencionar que, em decorrência do aumento de visibilidade, o Poder Judiciário "se tornou alvo" e "refém dos meios de comunicação social".

Essa midiatização tem como um de seus impactos a maior exposição do Poder Judiciário aos julgamentos da opinião pública. Por conseguinte, "as formas clássicas de intervenção no espaço público", com rituais e solenidades, não são mais suficientes para enfrentar os desdobramentos da "sociedade do espetáculo", exigindo que a comunicação da Justiça se modernize, até mesmo para enfrentar os ataques que contra ela são direcionados. (POIRMEUR, 2012, p. 110-111)

Nessa mesma linha, o interesse da sociedade e dos meios de comunicação quanto ao processo judicial adquire novas nuances. Esse sempre foi um tema conflituoso, tendo em vista a lógica própria do sistema de justiça no que concerne à construção da verdade e à presunção de inocência, sempre focada na preservação de garantias e na observância de todas as etapas necessárias para a legitimidade do exercício da prestação jurisdicional. O que há de particular na atualidade, como adverte Sammarco (2019, p. 28-29), é que, com as mídias digitais, 
as informações ou opiniões sobre o processo se difundem sem controle. Trata-se de um fluxo informativo "sem possibilidade concreta de ser neutralizado”. Qualquer pessoa pode emitir juízo de valor e influenciar incontáveis outras a seguir igual raciocínio, mesmo não tendo familiaridade com os ritos do sistema de Justiça e com os atos do processo. Desse modo, o processo midiático contemporâneo é guiado apenas pela "lógica da emoção", circunstância que se torna ainda mais preocupante quando aliada à velocidade de propagação das informações e à abrangência das redes. Certamente, essa realidade traz profundas repercussões para o que uma sociedade civilizada deve entender como julgamento legítimo.

Outro fenômeno também merece atenção: a midiatização das audiências. Esses atos processuais são, em regra, submetidos ao princípio da publicidade, contudo, mesmo assim não costumavam ser acessíveis ao grande público, notadamente diante das restrições de ingresso dos meios de comunicação nas salas de julgamentos, seja para gravação ou transmissão. A audiência judicial, como momento em que se realiza tentativa de esclarecimento dos fatos discutidos no processo, é ato que geralmente se reveste de complexidade, uma vez que envolve não só ritos legais, mas também, não raro, a manifestação de emoções e conflitos que circundam o caso trazido a juízo. Nesse contexto, a publicação de trechos selecionados e descontextualizados da audiência fornece uma perspectiva apenas parcial do processo. Mesmo assim, acaba sendo material suficiente para que se formem as mais diversas opiniões difundidas pela mídia tradicional ou pelas redes sociais. Refletindo sobre o tema, Poirmeur (2012, p. 168) pondera que, devido a uma série de fatores, essa midiatização da audiência "está longe de ser transparente e representativa do conteúdo dos debates", sobretudo em virtude dos vieses interpretativos que podem ser atribuídos ao ato, bem como da superficialidade da comunicação nas redes sociais.

O processo midiático, para além de levar a juízos precipitados sobre o que deveria ser o desfecho da demanda, concorre ainda para que a decisão do magistrado ou sua atuação durante determinado ato judicial seja objeto de amplo julgamento público, em que se questiona o comportamento do juiz, sua independência e imparcialidade. A propósito do tema, Sammarco (2019, p. 43-47) traz o caso emblemático do juiz Aaron Persky, na Califórnia, que foi alvo de intensa campanha midiática negativa por ter proferido sentença considerada excessivamente branda em caso de violência sexual, a 
ponto de perder o cargo mediante o instituto do recall. Certamente, a sociedade tem o direito de crítica sobre essas matérias. Mas o que requer atenção é a amplitude que esses movimentos podem tomar, o radicalismo de posicionamentos e a banalização da agressividade.

O interesse pelo Poder Judiciário, porém, ultrapassa as temáticas relacionadas a processos e ao funcionamento da instituição, acrescentando outro ponto, que é a exposição da vida privada dos magistrados. Assim, atitudes adotadas fora do exercício das atividades profissionais acabam adquirindo amplo destaque, repercutindo na imagem institucional, mediante a livre circulação das informações nas redes. A própria participação dos magistrados nas redes sociais também é circunstância passível de gerar conflitos entre as esferas pessoal e profissional, devido à conexão próxima existente entre ambas, em virtude da visibilidade e da representatividade que a magistratura tem.

Se a curiosidade popular sobre os temas relacionados à Justiça e as críticas dirigidas ao Poder Judiciário e seus membros são fenômenos antigos, certamente o fortalecimento dos meios de comunicação de massa e, posteriormente, a expansão deles para abranger as mídias digitais trouxeram novas possibilidades e também preocupações. Sobre os meios de comunicação tradicionais, como destaca Dufour (2019, p. 9-18), não se discute a importância deles para a sociedade democrática, contudo não se deve perder de vista o quanto o sistema midiático pode ser tóxico e orientado, em certa medida, pelo interesse de rentabilidade. Por outro lado, as redes sociais, movidas pela ausência de intermediação, apresentam forte potencial de pressionar as instituições, "exigindo que se adaptem à sua vontade". Mídia e Justiça sempre terão lógicas próprias de atuação e pontos de conflitos, o que se espera do Poder Judiciário é que seja cada vez mais capaz de compreender as transformações da sociedade, promovendo os ajustes necessários para manter a conexão com seu público, sem perder, porém, os princípios que Ihe são inerentes.

\section{COMUNICAÇÃO DO PODER JUDICIÁRIO E GESTÃO DE RISCOS NO PLANEJAMENTO ESTRATÉGICO}

A midiatização da Justiça na sociedade do espetáculo e da informação amplia as possibilidades de crises que geram repercussões negativas para o Poder Judiciário, fragilizando sua imagem. Os meios de 
comunicação tradicionais concorrem para que esses episódios aconteçam e continuem exigindo atenção, no entanto são as novas mídias digitais que têm potencial ainda maior de provocar danos, considerando a velocidade do fluxo da informação e a impossibilidade de controle daquilo que é propagado, correspondendo ou não à verdade. As peculiaridades do trânsito das informações no cenário atual provocam não só grandes crises, mas também promovem um "dia a dia recheado de pequenas crises, de diferentes intensidades e localizações” (FARIA, 2019, p. 94). É certo que não é razoável ter a pretensão de evitar completamente as crises, entretanto é imprescindivel que se adotem medidas para dar o tratamento adequado a essas situações, agindo com profissionalismo.

O desenvolvimento das mais diversas atividades humanas, pessoais e profissionais envolve a noção de risco. Os aprendizados sobre a administração dos riscos, impulsionados a partir do Renascimento e da construção da Teoria das Probabilidades, foram decisivos para o progresso tecnológico e para a realização de grandes empreendimentos 2 . Por outro lado, a complexidade dos cenários sociais contemporâneos é altamente propícia ao surgimento de novas modalidades de riscos ou à intensificação deles, com repercussões que podem assumir dimensões globais, a exemplo das questões ambientais e das epidemias.

A definição de risco, embora bastante variável, em regra, engloba a ideia de evento futuro e incerto apto a gerar impactos positivos ou negativos em uma determinada ação ou iniciativa ${ }^{3}$. Hillson e MurrayWebster (2007) esclarecem que todas as conceituações de risco convergem para dois elementos essenciais: incerteza e consequências, de maneira que um evento incerto, mas sem consequências, não pode ser caracterizado como risco. Considerando que os riscos são inerentes às atividades humanas, resta encontrar mecanismos de administrá-los. Nesse sentido, existem diversas metodologias de gerenciamento de riscos corporativos, sendo que, em regra, seguem um "ciclo básico", com etapas bem específicas.

Assim, o ponto de partida é a identificação dos riscos, os quais, em seguida, devem ser analisados, ponderando-se sobre a probabilidade de ocorrência e o impacto, o que resulta na confecção da matriz de risco. 0 próximo passo é a priorização desses riscos, conforme a relevância que se determine para eles. São esses critérios que vão nortear o tratamento dos

\footnotetext{
2 Para um estudo sobre a evolução histórica da administração dos riscos: Bernstein (1997).

3 Sobre as concepções de risco: Vasconcelos (2020, p. 35-38).
} 
riscos, ou seja, a definição da resposta mais adequada para a prevenção ou enfrentamento. Tais respostas podem ser, exemplificativamente, ações para evitar, mitigar, compartilhar ou transferir, ou ainda aceitar o risco. Por fim, cumpre realizar todos os cuidados de monitoramento. (VASCONCELOS, 2020, p. 60-74)

O Poder Judiciário, na execução de suas atividades, está, como qualquer outra instituição, sujeito a situações que podem interferir em suas estratégias, objetivos e projetos, sejam esses fatores decorrentes da realidade interna ou externa. Nesse contexto, enquadra-se o risco de exposição midiática com repercussões sobre a reputação institucional. Para o fortalecimento do Poder Judiciário na sociedade democrática, é fundamental que sua imagem esteja associada à imparcialidade, confiabilidade, segurança, correção, zelo na administração de recursos públicos, isonomia, eficiência, dentre outros qualificativos. Antever as situações que podem macular a percepção social relativa a esses valores e estabelecer respostas adequadas antes que as crises aconteçam é tarefa que precisa ser cada vez mais priorizada.

É necessário, assim, que a comunicação do Poder Judiciário com os jurisdicionados e, especificamente, sua relação com a mídia sejam objeto de constante atenção no planejamento estratégico institucional. Tal esforço requer ações direcionadas para construir o plano de gerenciamento da comunicação institucional, em que se reflita sobre as novas exigências de proximidade do Judiciário com o seu principal stakeho/der, que é o jurisdicionado, bem como sobre os parâmetros de convivência produtiva com os meios de comunicação de massa tradicionais, os quais também cumprem um papel fundamental de preservação da democracia. Além disso, há de se dispensar especial cuidado quanto às estratégias de uso das mídias digitais na comunicação institucional, tendo em vista as peculiaridades quanto à linguagem, ao tempo de reação e ao potencial de propagação.

Como complemento do plano de gerenciamento da comunicação, tem-se o plano de gestão dos riscos, em que o risco de mácula na reputação institucional decorrente de exposição midiática seja devidamente considerado, definindo-se o tratamento adequado para mitigar os danos inerentes aos momentos de crise. O nível de prioridade que se atribui a esse tipo de risco, na análise de probabilidade e impacto, vai ser decisivo para orientar a tomada de decisão quanto à distribuição de recursos financeiros e humanos para esse setor específico do Poder Judiciário. Aqui, importa ponderar também sobre qual a melhor 
abordagem para lidar com comportamentos individuais que podem gerar danos à imagem institucional, a exemplo da participação de magistrados nas redes sociais. Como destaca Lima (2019, p. 120-122), o gerenciamento de crises decorrentes da comunicação não deve levar em conta apenas a instituição, mas também as pessoas que a integram e que são passíveis de serem expostas tanto no desempenho de suas atividades profissionais quanto na vida privada.

Nesse ponto, podem ser previstas como ações preventivas o investimento em cursos de formação dos magistrados sobre como interagir com os meios de comunicação e atuar nas redes sociais com a prudência necessária. É essencial que o próprio magistrado aperfeiçoe sua percepção de risco, compreendendo a dinâmica das redes de comunicação da sociedade atual e antevendo desdobramentos de sua conduta. Para tanto, ajuda profissional e assessoramento disponibilizados pela instituição aos magistrados são medidas que fazem a diferença.

Por fim, resgatando a ideia apresentada acima, cabe lembrar que a noção de riscos não envolve apenas consequências negativas, embora esse seja o enfoque mais comumente ressaltado. De fato, o risco por vezes é tomado também na acepção positiva de oportunidade de ganhos. Nessa ótica, a visibilidade midiática pode favorecer a imagem do Poder Judiciário, contribuindo para que o público adquira mais conhecimento sobre a instituição e, assim, compreenda melhor sua importância para a sociedade.

Já não é, pois, admissível que as crises aconteçam sem que se tenha posturas preventivas e estratégias de atuação para atenuar danos à imagem institucional. Nesse sentido, o planejamento é o caminho imperativo para que se adquira maturidade na identificação e no tratamento dos desafios do Poder Judiciário. A própria consolidação de uma cultura de planejamento e de continuidade na execução das ações é tarefa que ainda encontra obstáculos e resistências. Ao se estabelecer planos de gestão da comunicação e dos riscos, que efetivamente orientem as condutas e a tomada de decisão, possibilita-se o melhor acompanhamento dessas temáticas e o aperfeiçoamento contínuo a partir das lições aprendidas. 


\section{CONCLUSÃO}

Durante muito tempo, o Poder Judiciário ocupou-se do exercício de suas funções, focado em procedimentos e linguagem próprios, sempre cauteloso em manter a distância necessária para preservar-se de influências externas, sobretudo da opinião pública. Muitas transformações sociais, porém, ocorreram, e, historicamente, de modo bastante rápido. Antigas práticas e valores tão cultivados nas instituições públicas, e que demarcavam unilateralmente o espaço do poder e do cidadão, deixaram de ser aceitáveis e foram mesmo coibidos por novos marcos legais. Por consequência, também o Poder Judiciário viu-se chamado a estabelecer um novo paradigma de atuação, em que a transparência, a acessibilidade e a proximidade tornaram-se parâmetros inafastáveis.

Não obstante a importância conferida ao Poder Judiciário no Estado Democrático de Direito, a percepção social de legitimidade da Justiça não é resultado automático, mas fruto de um conjunto de fatores, dentre eles a relação de confiança que vai sendo construída a partir de ações pautadas em inclusão, respeito, imparcialidade e comunicação eficiente voltada para a cidadania. Essa base é fundamental para dar ao Poder Judiciário o suporte necessário em momentos de crise.

Não basta, porém, que o Poder Judiciário se reinvente enquanto instituição, se essas mudanças não forem adequadamente percebidas pela sociedade. Nesse ponto, a reflexão direciona-se para a comunicação institucional, que deve ser pensada estrategicamente como instrumento de divulgar as boas práticas, de captar os anseios do cidadão que carece da prestação jurisdicional e de promover mais conhecimento sobre o funcionamento da Justiça.

Por variadas razões, a forma como o Poder Judiciário se comunica com a sociedade erige-se a tema de particular importância, sobretudo nesse momento sociocultural e histórico em que a informação e a imagem adquirem poder sem precedentes. Quando esse diálogo é intermediado pelos meios de comunicação, surgem problemas específicos relacionados à lógica que inspira esses veículos e, que, em certos aspectos, entra em conflito com a dinâmica própria da Justiça. Contudo, a posição clássica de afastamento por receio de interferências já não é sustentável, notadamente diante do papel que a mídia desempenha na formação da opinião pública. Para além disso, o advento das mídias digitais impôs seu ritmo e sua 
linguagem, mas também abriu novos canais de participação cidadã e oportunidades de reinvenção da comunicação institucional da Justiça.

A relação entre Poder Judiciário e mídia deve, portanto, ser compreendida dentro de um cenário social caracterizado pela informação rápida e proveniente de diversas fontes, pela pluralidade de formadores de opinião, pela dificuldade de controle do que é veiculado e, não raro, pelas fake news. É também um contexto em que a informação difundida pode gerar impactos de difícil reparação, fomentando crises institucionais que comprometem a imagem e a credibilidade. A exposição midiática traz a crise, como consequência negativa, mas, igualmente, as oportunidades de reforçar a relevância social do Poder Judiciário. A maturidade institucional, adquirida com planejamento, continuidade e profissionalização de suas estratégias comunicativas, certamente ajudará a construir o melhor caminho. 


\section{REFERÊNCIAS}

AMB; FGV; IPESPE. Estudo da imagem do Judiciário brasileiro. Brasília: AMB, 2019. Disponível em: https://www.amb.com.br. Acesso em: 10 abr. 2021.

ARNAUD, André-Jean. Entre modernité et mondialisation: leçons d'histoire de la philosophie du droit et de l'État. 2e. éd. Paris: LGDJ, 2004.

AUBERT, Nicole. Le culte de l'urgence: la société malade du temps. Paris: Flammarion, 2003.

BAUMAN, Zygmunt. Modernidade líquida. Trad. Plínio Dentzein. Rio de Janeiro: Jorge Zahar, 2001.

BENTIVEGNA, S.; ARTIERI, G. Boccia. Le teorie delle comunicazioni di massa e la sfida digitale. Bari-Roma: Laterza, 2019.

BERNSTEIN, Peter L. Desafio aos deuses: a fascinante história do risco. Trad. Ivo Korytowski. Rio de Janeiro: Elsevier, 1997.

BINDER, Alberto M. Justicia penal y estado de derecho. 2. ed. Buenos Aires: Ad-Hoc, 2004.

BITTAR, Eduardo C. B. O direito na pós-modernidade. Rio de Janeiro: Forense Universitária, 2005.

CASTELLS, Manuel. O poder da comunicação. Trad. Vera Lúcia Mello Joscelyne. 2. ed. São Paulo: Paz e Terra, 2017.

CASTELLS, Manuel. A sociedade em rede. Trad. Roneide Venacio Majer. 21. ed. São Paulo: Paz e Terra, 2020.

CASTRO, Aline. Comunicação pública como cultura organizacional. In: NASSAR, Paulo; SANTOS, Hamilton dos (org.). Comunicação pública: por uma prática mais republicana. São Paulo: Aberje, 2019.

CHEVALLIER, Jacques. Le mythe de la transparence administrative. In: Information et transparence administratives. Paris: PUF, 1988. Disponível em: https://www.u-picardie.fr/curapp-revues/root/21/chevallier.pdf. Acesso em: 12 abr. 2021. 
DUARTE, Jorge; DUARTE, Marcia Yukiko. Serviço público, comunicação e cidadania. In: NASSAR, Paulo; SANTOS, Hamilton dos (org.).

Comunicação pública: por uma prática mais republicana. São Paulo: Aberje, 2019.

DUFOUR, Olivia. Justice et médias: la tentation du populisme. Paris: LGDJ, 2019.

FARIA, Armando Medeiros. A comunicação entre o previsível e o improvável. In: NASSAR, Paulo; MARETTI, Eduardo (org.). Comunicação pública: por uma prática mais republicana. São Paulo: Aberje, 2019.

FERRARESE, Maria Rosaria. II diritto al presente: globalizzazione e tempo delle istituzioni. Bologna: II Mulino, 2002.

HAN, Byung-Chul. Sociedade da transparência. Trad. Enio Paulo Giachini. Petrópolis: Vozes, 2017.

HAN, Byung-Chul. No enxame: perspectivas do digital. Trad. Lucas Machado. Petrópolis: Vozes, 2019.

HARVEY, David. Condição pós-moderna. Trad. Adail Ubirajara Sobral; Maria Stela Gonçalves. 15. ed. São Paulo: Loyola, 2006.

HILLSON, David; MURRAY-WEBSTER, Ruth. Understanding and managing risk attitude. 2 nd ed. Aldershot: Gower, 2007. E-book.

IANNI, Octavio. A era do globalismo. 8. ed. Rio de Janeiro: Civilização Brasileira. 2004.

LIMA, Anna Ruth Dantas de Sales Ferreira. O comitê permanente em empresas públicas e privadas. In: NASSAR, Paulo; MARETTI, Eduardo (org.). Comunicação pública: por uma prática mais republicana. São Paulo: Aberje, 2019.

POIRMEUR, Yves. Justice et médias. Paris: LGDJ, 2012.

SAMMARCO, Pieremilio. Giustizia e social media. Bologna: II Mulino, 2019.

SANTOS, Boaventura de Sousa. Para uma revolução democrática da Justiça. 3. ed. São Paulo: Cortez, 2011.

VASCONCELOS, Fernando Freire. Gestão de risco no Poder Judiciário. Belo Horizonte: Dialética, 2020. 